\title{
Serum lactate dehydrogenase levels predict the prognosis of patients with soft tissue sarcoma
}

\author{
TAKETSUGU FUJIBUCHI, HIROSHI IMAI, TERUKI KIDANI, TADAO MORINO and HIROMASA MIURA
}

Department of Bone and Joint Surgery, Ehime University Graduate School of Medicine, Toon, Ehime 791-0295, Japan

Received October 17, 2021; Accepted January 12, 2022

DOI: $10.3892 / \mathrm{mco} .2022 .2498$

\begin{abstract}
Several studies have reported the prognostic factors for soft tissue sarcoma. Although serum lactate dehydrogenase (LDH) levels are associated with poor prognosis in several types of cancer, their role in soft tissue sarcomas remains unclear. Therefore, the present study evaluated the association between serum LDH levels and the clinical characteristics and prognosis of soft tissue sarcoma. A total of 103 patients diagnosed with primary soft tissue sarcoma between 2003 and 2019 were retrospectively examined, and the association between serum LDH levels at the first visit and clinical characteristics were analysed. In high-grade soft tissue sarcoma, the association between survival and clinical characteristics, including stratified LDH levels, was also analysed. Serum LDH levels were stratified (>253 and $\leq 253$ IU/1) according to the standard values used at our institution. High serum LDH levels were significantly associated with the presence of metastasis and histological grade $(\mathrm{P}<0.001$ and 0.040 , respectively). In both the univariate and multivariate analyses, disease-specific survival (DSS) was significantly worse in patients with high-grade soft tissue sarcoma and high serum LDH levels than in patients with normal serum LDH levels (univariate analysis: $\mathrm{P}=0.025$; multivariate analysis: Hazard ratio, 4.60; $95 \%$ confidence interval, 1.16-18.2; $\mathrm{P}=0.030)$. In conclusion, high serum LDH levels at the first visit predicted the presence of distant metastasis, high histological grade and worse DSS in patients with high-grade soft tissue sarcoma. Therefore, in patients with high serum LDH levels at the first visit, these risks should be considered during pretreatment examinations and post-treatment follow-up.
\end{abstract}

Correspondence to: Dr Taketsugu Fujibuchi, Department of Bone and Joint Surgery, Ehime University Graduate School of Medicine, 454 Shitsukawa, Toon, Ehime 791-0295, Japan

E-mail: buchi@m.ehime-u.ac.jp

Abbreviations: LDH, lactate dehydrogenase; CRP, C-reactive protein; WBC, white blood cell; Hb, haemoglobin; DSS, diseasespecific survival; DFS, disease-free survival

Key words: soft tissue sarcoma, LDH, metastasis, prognosis, Warburg effect

\section{Introduction}

Predicting the prognosis of soft tissue sarcomas remains a major challenge for orthopaedic oncologists. Several reports regarding the prognostic factors for soft tissue sarcoma, including age and tumour size, depth, location, and histological grade, have already been published (1). However, except for serum C-reactive protein (CRP) levels (2-4), there are few reports on the prognostic biomarkers for soft tissue sarcoma, including lactate dehydrogenase (LDH).

$\mathrm{LDH}$ is a ubiquitous enzyme among vertebrates that catalyses the interconversion of pyruvate and lactate with the concurrent interconversion of nicotinamide adenine dinucleotide (NAD+) and reduced nicotinamide adenine dinucleotide (NADH). In most cells, glucose is metabolized to pyruvate via glycolysis. During oxidative phosphorylation, most of the pyruvate gets completely oxidized to $\mathrm{CO}_{2}$ within the mitochondria in the presence of abundant oxygen. During oxygen shortage, pyruvate is redirected away from mitochondrial oxidative phosphorylation via anaerobic glycolysis to generate lactate. In normal cells, lactate is produced via anaerobic glycolysis only during oxygen deficiency. However, in cancer cells, most of the glucose is converted to lactate, regardless of the presence of oxygen. Aerobic glycolysis is known as the Warburg effect (5-7). LDH exists as five major isoenzymes, labelled LDH-1-5. It is formed by the association between two different subunits, $\mathrm{M}$ and $\mathrm{H}$, and encoded by two different genes, $l d h-a$ and $l d h-b$. LDH- 1 and LDH-5 are commonly known as LDHB and LDHA, respectively. The isozyme profile ratio of the LDH isozyme is tissue specific. Tumour tissues express LDH-4 and LDH-5, which play a role in aerobic glycolysis (8).

Clinically, serum LDH levels are used for the late detection of myocardial infarction and the diagnosis of haemolytic anaemia (9); it also has clinical importance in cancer. Several studies have reported an association between high LDH levels and poor prognosis in several cancers, including renal cell carcinoma, nasopharyngeal carcinoma, melanoma, prostate cancer, colorectal cancer, and lung cancer (10). Reports suggest that a high serum LDH level is a predictive factor for poor overall survival in a few histological types, such as osteosarcoma and Ewing sarcoma (11-16). In past report, we revealed that serum LDH level was one of the diagnostic factors for soft tissue sarcoma, however, we could not make reference to whether serum LDH level was a prognostic factor for soft tissue sarcoma (17). 
There are few reports on the association between serum LDH levels and the prognosis of soft tissue sarcoma and whether it is a prognostic factor remains unclear. Thus, this study evaluated the association between serum LDH levels and clinical characteristics of soft tissue sarcomas, as well as the prognostic impact of serum LDH levels.

\section{Patients and methods}

Patients. Medical records of 138 patients with soft tissue sarcoma treated in our hospital between April 2003 and March 2019 were retrospectively reviewed. Tumours belonging to the intermediate group were excluded, for example, atypical lipomatous tumour/well differentiated liposarcoma. Thirty-five patients treated after an unplanned resection or referred for additional treatment were excluded; the remaining 103 patients were included. Blood tests, including white blood cell (WBC) count, haemoglobin $(\mathrm{Hb})$ level, serum CRP level, and serum LDH level, were performed for all patients during their first visit to our hospital. Tumour size was defined as the maximum diameter of the tumour mass on magnetic resonance imaging. Histological diagnosis and histological grade determination were made using a core needle, incisional biopsy, or excisional biopsy. Histologic grade 1 was classified as low grade and grades 2 and 3 were classified as high grade. Computed tomography was performed to screen for distant metastasis. Serum CRP and LDH levels were tested using an automated clinical chemistry analyser TBA-200SR (Toshiba Medical Systems) from April 2003 to February 2011 and TBA-c16000 (Canon medical systems corporation, Tochigi, Japan) from March 2011 to March 2019. The associations between serum LDH levels with age, sex, tumour depth, tumour size, presence or absence of distant metastases, histological grade, histological diagnosis, WBC count, Hb level, and serum CRP level were analysed. Disease-specific survival (DSS) and disease-free survival (DFS) were analysed using stratified clinical characteristics. Age was stratified as $<71$ and $\geq 71$ years according to the median value of analysed patients, and tumour sizes were stratified as $<5.0$ and $\geq 5.0 \mathrm{~cm}$ according to a past report (18). Regarding laboratory test values, WBC count was stratified as $\leq 9,100 / \mu \mathrm{l}$ and $>9,100 / \mu \mathrm{l}$, Hb level as $<11.3$ and $\geq 11.3 \mathrm{~g} / \mathrm{dl}$, serum CRP level as $\leq 0.20$ and $>0.20 \mathrm{mg} / \mathrm{dl}$, and serum LDH level as $\leq 253$ and $>253 \mathrm{IU} / 1$, which are the standard values used at our institution. Survival rate analysis was performed for high-grade soft tissue sarcomas. Patients with distant metastasis at the first visit were excluded from the survival rate analysis and only patients with a tumour-free status during treatment initiation were included in the DFS analysis. DSS was defined as the interval between the date of the first visit to our hospital and the date of death. DFS was defined as the interval between the initiation of primary treatment and the diagnosis of local recurrence or distant metastasis.

Statistical analysis. Associations between serum LDH levels and clinical characteristics were evaluated using the Mann-Whitney U test or Kruskal-Wallis test for categorical data and Spearman's rank correlation coefficient for continuous data. Survival curves were constructed using the Kaplan-Meier method. The log-rank test was used to compare the survival of patients with clinical characteristics.

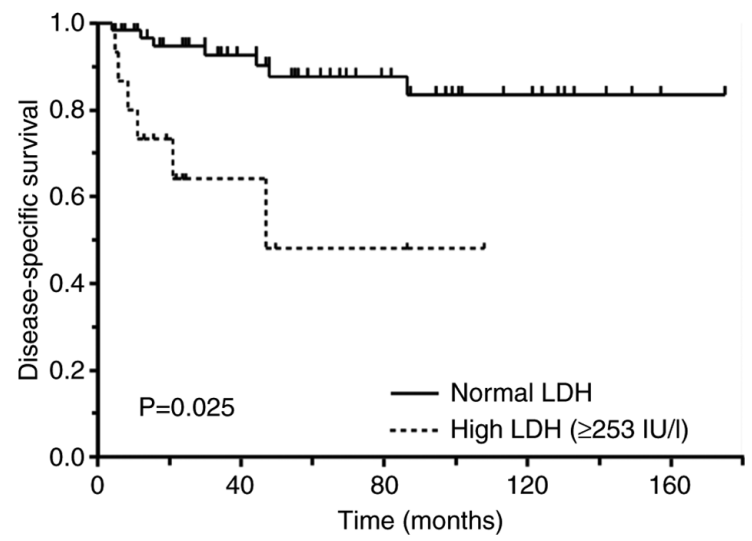

Figure 1. Disease-specific survival according to serum LDH levels. The 5-year disease-specific survival rate was $82.1 \%$ in patients with normal LDH levels and $60.6 \%$ in patients with high LDH levels. Patients with high serum LDH levels also had significantly worse disease-specific survival than those with a normal LDH levels $(\mathrm{P}=0.025)$. $\mathrm{LDH}$, lactate dehydrogenase.

Multivariate analyses for DSS were performed using the Cox proportional hazards model. Significant variables identified in the univariate analysis were evaluated in a multivariable analysis. Statistical analyses were performed using JMP ${ }^{\circledR} 14$ (SAS Institute Inc.). $\mathrm{P}<0.05$ was considered to indicate a statistically significant difference.

\section{Results}

Patient demographics of all 103 patients. This study included 61 men and 42 women. Twenty-eight of the included tumours were superficial, and 75 were deep. The median age was 66.0 (range, 2-96) years. The median tumour size was 8.9 (1.0-31.6) $\mathrm{cm}$. The median WBC count was $6,400(1,900-18,100) / \mu 1$. The median Hb level was $13.2(6.3-17.4) \mathrm{g} / \mathrm{dl}$. The median serum CRP level was $0.26(0.01-21.2) \mathrm{mg} / \mathrm{dl}$. The median serum LDH level was $182(21-2,014)$ IU/1. The most diagnosed tumour was malignant fibrous histiocytoma/undifferentiated pleomorphic sarcoma, followed by liposarcoma; the most common location was the thigh, followed by the lower leg (Table I). Of all 103 patients, there were 86 patients with high histological grades, and 12 patients with low histological grades. Data on the histological grade of five patients were not available. Treatment methods are shown in Table I.

Serum LDH levels and clinical characteristics. There was a significant association between the presence/absence of distant metastasis at the first visit and serum LDH levels $(\mathrm{P}<0.001)$ and tumour grade $(\mathrm{P}=0.040)$ (Table II). Age, sex, tumour depth, tumour size, laboratory test results, and histological diagnosis did not correlate with serum LDH levels (Table III).

DSS and clinical characteristics. There were 21 patients with distant metastasis and 12 patients with low-grade tumours. As a result, DSS analysis was performed for 70 patients with high-grade soft tissue sarcomas without distant metastasis at the first visit. In the univariate analysis, patients with high serum LDH levels had significantly worse DSS than patients with normal serum LDH levels $(\mathrm{P}=0.025)$ (Fig. 1). Older patients had worse DSS than younger patients $(\mathrm{P}=0.016)$ and 
Table I. Histological diagnosis, location of tumours, and treatment of all 103 patients.

\begin{tabular}{|c|c|}
\hline Characteristics & Number of patients \\
\hline \multicolumn{2}{|l|}{ Histological diagnosis } \\
\hline MFH/UPS & 23 \\
\hline Liposarcoma & 20 \\
\hline Myxoid liposarcoma & 9 \\
\hline Pleomorphic liposarcoma & 6 \\
\hline Dedifferentiated liposarcoma & 5 \\
\hline Leiomyosarcoma & 18 \\
\hline Myxofibrosarcoma & 11 \\
\hline MPNST & 8 \\
\hline Synovial sarcoma & 6 \\
\hline Rhabdomyosarcoma & 5 \\
\hline Ewing sarcoma & 3 \\
\hline Other histologic types & 9 \\
\hline \multicolumn{2}{|l|}{ Tumour location } \\
\hline Thigh & 52 \\
\hline Lower leg & 8 \\
\hline Buttock & 7 \\
\hline Retroperitoneum & 6 \\
\hline Upper arm & 5 \\
\hline Back & 4 \\
\hline Shoulder girdle & 3 \\
\hline Chest wall & 3 \\
\hline Abdominal wall & 3 \\
\hline Forearm & 3 \\
\hline Hand & 2 \\
\hline Other locations & 7 \\
\hline \multicolumn{2}{|l|}{ Treatment } \\
\hline Surgery alone & 64 \\
\hline Surgery + RT & 7 \\
\hline Surgery + CT & 17 \\
\hline Surgery + RT + CT & 2 \\
\hline RT alone & 3 \\
\hline CT alone & 3 \\
\hline $\mathrm{RT}+\mathrm{CT}$ & 3 \\
\hline BST & 4 \\
\hline
\end{tabular}

MFH/UPS, malignant fibrous histiocytoma/undifferentiated pleomorphic sarcoma; MPNST, malignant peripheral nerve sheath tumour; RT, radiotherapy; CT, chemotherapy; BST, best supportive care.

patients with high-grade soft tissue sarcomas $(\mathrm{P}=0.035)$. Sex, tumour depth, tumour size, WBC count, Hb levels, and serum CRP levels were not associated with DSS. In the multivariate analysis, older age (hazard ratio [HR], 5.86; 95\% confidence interval [CI], 1.35-25.3; $\mathrm{P}=0.018$ ) and high serum $\mathrm{LDH}$ levels (HR, 4.60; 95\% CI, 1.16-18.2; $\mathrm{P}=0.030$ ) were poor prognostic factors (Table IV).

Clinical characteristics of patients with high serum $L D H$ level. There were 12 patients with high serum LDH level
Table II. Associations between serum LDH levels and clinical characteristics with categorical data of all 103 patients.

\begin{tabular}{|c|c|c|c|}
\hline & $\begin{array}{l}\text { Number of } \\
\text { patients }\end{array}$ & $\begin{array}{c}\text { Mean serum LDH } \\
\text { levels (IU/l) }\end{array}$ & P-value \\
\hline Sex & & & 0.098 \\
\hline Male & 61 & 201.4 & \\
\hline Female & 42 & 288.1 & \\
\hline Tumour depth & & & 0.69 \\
\hline Superficial & 28 & 219.3 & \\
\hline Deep & 75 & 243.3 & \\
\hline Metastasis & & & $<0.001$ \\
\hline M0 & 82 & 199.9 & \\
\hline M1 & 21 & 380.6 & \\
\hline Histological grade & & & 0.040 \\
\hline Low grade & 12 & 194.0 & \\
\hline High grade & 86 & 232.4 & \\
\hline Histological diagnosis & & & 0.41 \\
\hline MFH/UPS & & 195.8 & \\
\hline Liposarcoma & & 189.8 & \\
\hline Leiomyosarcoma & & 214.9 & \\
\hline Myxofibrosarcoma & & 228.0 & \\
\hline MPNST & & 191.0 & \\
\hline Synovial sarcoma & & 243.3 & \\
\hline Rhabdomyosarcoma & & 402.8 & \\
\hline Ewing sarcoma & & 842.3 & \\
\hline $\begin{array}{l}\text { Other histologic } \\
\text { types }\end{array}$ & & 242.0 & \\
\hline
\end{tabular}

LDH, lactate dehydrogenase; M0, absence of metastasis; M1, presence of distant metastasis; MFH/UPS, malignant fibrous histiocytoma/undifferentiated pleomorphic sarcoma; MPNST, malignant peripheral nerve sheath tumour.

Table III. Correlations between serum LDH levels and clinical characteristics with continuous data.

\begin{tabular}{lcc}
\hline Characteristic & Spearman's $\rho$ & P-value \\
\hline Age & -0.0060 & 0.55 \\
Tumour size & 0.0625 & 0.53 \\
WBC count & 0.0724 & 0.47 \\
Hb level & -0.0344 & 0.73 \\
Serum CRP level & -0.0140 & 0.89 \\
\hline
\end{tabular}

LDH, lactate dehydrogenase; WBC, white blood cell; Hb, haemoglobin; CRP, C-reactive protein.

(>253 IU/1) in the group of patients analysed for DSS rate. The most common histological diagnosis was myxofibrosarcoma (four patients), followed by malignant fibrous histiocytoma/undifferentiated pleomorphic sarcoma (two patients). Pleomorphic liposarcoma, leiomyosarcoma, rhabdomyosarcoma, Ewing sarcoma, synovial sarcoma, and CIC 
Table IV. Disease-specific survival and clinical characteristics.

\begin{tabular}{|c|c|c|c|c|c|c|}
\hline \multirow[b]{2}{*}{ Characteristic } & \multicolumn{3}{|c|}{ Univariate analysis } & \multicolumn{3}{|c|}{ Multivariate analysis } \\
\hline & Number of patients & 5-year DSS (\%) & P-value & Hazard ratio & $95 \% \mathrm{CI}$ & P-value \\
\hline Age & & & 0.016 & & & \\
\hline Younger (<71 years) & 32 & 92.1 & & & & \\
\hline Older ( $\geq 71$ years) & 38 & 61.0 & & 5.86 & $1.35-25.3$ & 0.018 \\
\hline Sex & & & 0.81 & & & \\
\hline Male & 38 & 76.7 & & & & \\
\hline Female & 32 & 76.3 & & & & \\
\hline Tumour depth & & & 0.39 & & & \\
\hline Superficial & 21 & 74.2 & & & & \\
\hline Deep & 49 & 78.5 & & & & \\
\hline Tumour size & & & 0.44 & & & \\
\hline Small $(<5.0 \mathrm{~cm})$ & 19 & 88.9 & & & & \\
\hline Large $(\geq 5.0 \mathrm{~cm})$ & 61 & 75.2 & & & & \\
\hline Grade & & & 0.035 & & & \\
\hline 2 & 30 & 92.7 & & & & \\
\hline 3 & 40 & 65.3 & & 3.09 & $0.67-14.3$ & 0.15 \\
\hline WBC count & & & 0.84 & & & \\
\hline $\operatorname{Normal}(\leq 9,100 / \mu 1)$ & 25 & 76.8 & & & & \\
\hline $\operatorname{High}(>9,100 / \mu \mathrm{l})$ & 57 & 80.0 & & & & \\
\hline Hb level & & & 0.59 & & & \\
\hline Low $(<11.3 \mathrm{~g} / \mathrm{dl})$ & 15 & 68.8 & & & & \\
\hline Normal $(\geq 11.3 \mathrm{~g} / \mathrm{dl})$ & 55 & 79.6 & & & & \\
\hline Serum CRP level & & & 0.28 & & & \\
\hline Normal $(\leq 0.20 \mathrm{mg} / \mathrm{dl})$ & 28 & 84.5 & & & & \\
\hline $\operatorname{High}(>0.20 \mathrm{mg} / \mathrm{dl})$ & 42 & 72.7 & & & & \\
\hline Serum LDH level & & & 0.025 & & & \\
\hline Normal ( $\leq 253$ IU/l) & 58 & 82.1 & & & & \\
\hline High (>253 IU/l) & 12 & 60.6 & & 4.60 & $1.16-18.2$ & 0.030 \\
\hline
\end{tabular}

DSS, disease-specific survival; CI, confidence interval; WBC, white blood cell; Hb, haemoglobin; CRP, C-reactive protein; LDH, lactate dehydrogenase.

rearranged sarcoma were one case each. There were seven older patients, eight women, seven deep-seated tumours, 10 large tumours, three patients with high WBC counts, two with low Hb levels, and eight with high serum CRP levels in this group. During the observation period, local recurrence or distant metastasis was observed in six patients, and four patients died of disease.

DFS and clinical characteristics. Only best supportive care was given to two of 70 patients who underwent DSS analysis. Therefore, DFS was analysed for 68 patients. Patients with large tumour sizes had significantly worse DFS than those with small tumour size $(\mathrm{P}=0.026)$. Age, sex, tumour depth, tumour grade, WBC count, Hb levels, serum CRP level, and serum LDH level were not associated with DFS. The multivariate analysis was not performed because the only variable that showed a significant value in univariate analysis was tumour size (Table V).

\section{Discussion}

This study demonstrated that soft tissue sarcoma patients with metastases at the first visit and high histological grade showed high serum LDH levels. Patients with high serum LDH levels showed poor DSS in both the univariate and multivariate analyses.

Several previous studies and reviews have investigated the prognostic factors associated with soft tissue sarcomas. Tumour size and grade are well-known prognostic factors $(1,19)$. Older adults had worse survival compared with adolescents and young adults of all histologic subtypes $(20,21)$. Regarding biomarkers, the pre-treatment serum CRP levels were correlated with the prognosis $(2,22)$, and the neutrophil-to-lymphocyte ratio was also associated with the prognosis of soft tissue sarcoma $(23,24)$. Thus, pre-treatment high systemic inflammation is implicated in the poor prognosis of sarcoma (25). Furthermore, fibrinogen/albumin rate (26) 
Table V. Disease-free survival and clinical characteristics.

\begin{tabular}{|c|c|c|c|}
\hline \multirow[b]{2}{*}{ Characteristic } & \multicolumn{3}{|c|}{ Univariate analysis } \\
\hline & $\begin{array}{l}\text { Number } \\
\text { of patients }\end{array}$ & $\begin{array}{c}\text { 5-year } \\
\text { DFS (\%) }\end{array}$ & P-value \\
\hline Age & & & 0.15 \\
\hline Younger (<71 years) & 32 & 54.9 & \\
\hline Older ( $\geq 71$ years $)$ & 36 & 39.2 & \\
\hline Sex & & & 0.41 \\
\hline Male & 37 & 42.1 & \\
\hline Female & 31 & 51.6 & \\
\hline Tumour depth & & & 0.96 \\
\hline Superficial & 21 & 42.7 & \\
\hline Deep & 47 & 46.2 & \\
\hline Tumour size & & & 0.026 \\
\hline Small $(<5.0 \mathrm{~cm})$ & 9 & 88.9 & \\
\hline Large $(\geq 5.0 \mathrm{~cm})$ & 59 & 39.3 & \\
\hline Grade & & & 0.37 \\
\hline 2 & 29 & 51.0 & \\
\hline 3 & 39 & 42.9 & \\
\hline WBC count & & & 0.061 \\
\hline Normal $(\leq 9,100 / \mu \mathrm{l})$ & 59 & 50.5 & \\
\hline $\operatorname{High}(>9,100 / \mu 1)$ & 9 & 19.1 & \\
\hline Hb level & & & 0.27 \\
\hline Low $(<11.3 \mathrm{~g} / \mathrm{dl})$ & 14 & 35.9 & \\
\hline Normal ( $\geq 11.3 \mathrm{~g} / \mathrm{dl})$ & 54 & 50.0 & \\
\hline Serum CRP level & & & 0.19 \\
\hline Normal $(\leq 0.20 \mathrm{mg} / \mathrm{dl})$ & 28 & 56.0 & \\
\hline High $(>0.20 \mathrm{mg} / \mathrm{dl})$ & 40 & 39.2 & \\
\hline Serum LDH level & & & 0.33 \\
\hline Normal ( 253 IU/1) & 56 & 48.8 & \\
\hline High (>253 IU/1) & 12 & 44.4 & \\
\hline
\end{tabular}

DFS, disease-free survival; WBC, white blood cell; $\mathrm{Hb}$, haemoglobin; $\mathrm{CRP}, \mathrm{C}$-reactive protein; $\mathrm{LDH}$, lactate dehydrogenase.

and $\mathrm{Hb}$ levels (27) were reported as prognostic biomarkers for soft tissue sarcomas. Regarding serum LDH level, there were some reports of an association between LDH levels and prognosis in certain sarcomas. High LDH levels were a significant predictive factor for DFS or overall survival in patients with osteosarcoma (11-13) and Ewing sarcoma $(15,28)$. In addition, LDH levels are reportedly diagnostic, prognostic, and predictive markers of the therapeutic response in many cancers $(8,10,29)$, including renal cell carcinoma (30), nasopharyngeal carcinoma (31), melanoma (32), prostate cancer (33), colorectal cancer (34), and lung cancer (35).

In this study, the univariate analysis demonstrated that DSS was associated with age, tumour grade, and serum LDH levels. In the multivariate analysis, older age and high serum LDH levels were predictors of poor DSS. As for DFS, significant variables were not found. Some variables have been reported as prognostic factors of soft tissue sarcoma. There were a few discrepancies between our results and past reports. Soft tissue sarcoma is a group of tumours which are highly heterogeneous and have various characteristics. Differences in the distribution of histological type, study sizes, patient recruitment criteria, and biomarker thresholds might have resulted in inconsistencies. There was one report showing that a high serum LDH level was not a poor prognostic factor for soft tissue sarcoma. Although it is probably the median value, the paper showing different results did not clearly stipulate the threshold of LDH level (36). Our results revealed that a high serum LDH level above our laboratory standard of $253 \mathrm{IU} / 1$ is a poor prognostic factor for DSS in patients with soft tissue sarcoma. And we are in a position to support this result.

LDH plays a significant role in the Warburg effect that occurs during cancer cell metabolism. In normal cells, LDH activity and pyruvate production increases during certain stress conditions, specifically tissue injury, necrosis, hypoxia, haemolysis, and myocardial infarction. In contrast, the upregulation of LDH activity in cancer cells is not associated with stress conditions. Thus, the oxygen dependency of cancer cells is reduced (5-7). Additionally, the damage of surrounding soft tissue due to tumour growth can elevate LDH levels $(8,29)$. Activity of soft tissue sarcoma cell and tumour growth effect serum LDH levels, therefore, high serum LDH levels may be correlated with presence of distant metastasis, high histological grade, and poor prognosis in patients with soft tissue sarcoma.

This study had some limitations. First, our sample size was smaller than that of a similar existing study on other prognostic factors. Secondly, there were some uncertainties about the clinical significance of high serum LDH levels in patients with soft tissue sarcoma. For example, serum LDH level is affected by general conditions other than soft tissue sarcoma such as tissue injury, necrosis, hypoxia, haemolysis, and myocardial infarction. However, LDH isozymes were not distinguished in this study; tumour tissues expressed LDH-4 and LDH-5 specifically. Therefore, the levels of other isoenzymes may have been elevated owing to other mechanisms. As another uncertainty, this study defined our laboratory standard of $253 \mathrm{IU} / 1$ as a threshold, which varies according to reports. Therefore, it is impossible to define high serum LDH levels strictly and it should be aware of this point when describing the word 'high serum LDH levels'. Finally, soft tissue sarcoma is a group of tumours with many histological types and heterogeneous characteristics, though, this study could not analyse the significance of serum LDH level for each histological type. These points should be addressed in future studies.

In conclusion, this study revealed that high serum LDH levels predict the presence of distant metastasis, high histological grade, and worse DSS in patients with high-grade soft tissue sarcomas. In patients with high serum LDH levels at the first visit, we should keep these risks in mind during pretreatment examinations and post-treatment follow-up.

\section{Acknowledgements}

The authors are grateful to the late Dr Joji Miyawaki (Department of Bone and Joint Surgery, Ehime University Graduate School of Medicine) for valuable discussions. 


\section{Funding}

No funding was received.

\section{Availability of data and materials}

The datasets used and/or analysed during the current study are available from the corresponding author on reasonable request.

\section{Authors' contributions}

TF designed this study and drafted the manuscript. HI and HM gave advice on study design. TF and TK treated patients and collected patient data. TF and TK confirm the authenticity of all raw data. TM performed statistical analysis. TF, TK, HI and HM analysed and interpreted data. All authors read and approved the final manuscript.

\section{Ethics approval and consent to participate}

Ethics approval was obtained from the Institutional Review Board of the Ehime University Hospital (approval no. 1510010) and all study procedures were performed following the Declaration of Helsinki. The requirement for informed consent was waived owing to the retrospective nature of the study and the lack of identifiable patient information.

\section{Patient consent for publication}

Not applicable.

\section{Competing interests}

The authors declare that they have no competing interests.

\section{References}

1. Maretty-Nielsen K: Prognostic factors in soft tissue sarcoma Dan Med J 61: B4957, 2014.

2. Nakamura T, Matsumine A, Matsubara T, Asanuma K, Uchida A and Sudo A: Clinical significance of pretreatment serum C-reactive protein level in soft tissue sarcoma. Cancer 118 $1055-1061,2012$

3. Nakamura T, Matsumine A, Matsubara T, Asanuma K, Uchida A and Sudo A: The combined use of the neutrophil-lymphocyte ratio and C-reactive protein level as prognostic predictors in adult patients with soft tissue sarcoma. J Surg Oncol 108: 481-485, 2013

4. Choi ES, Kim HS and Han I: Elevated preoperative systemic inflammatory markers predict poor outcome in localized soft tissue sarcoma. Ann Surg Oncol 21: 778-785, 2014.

5. Warburg O: On the orign of cancer cells. Science 123: 309-314, 1956.

6. Markert CL: Lactate dehydrogenase. Biochemistry and function of lactate dehydrogenase. Cell Biochem Funct 2: 131-134, 1984.

7. Vander Heiden MG, Cantley LC and Thompson CB: Understanding the warburg effect: The metabolic requirements of cell proliferation. Science 324: 1029-1033, 2009.

8. Gallo M, Sapio L, Spina A, Naviglio D, Calogero A and Naviglio S: Lactic dehydrogenase and cancer: An overview. Front Biosci (Landmark Ed) 20: 1234-1249, 2015.

9. Huijgen HJ, Sanders GTB, Koster RW, Vreeken J and Bossuyt PMM: The clinical value of lactate dehydrogenase in serum: A quantitative review. Clin Chem Lab Med 35: 569-580, 1997.

10. Zhang J, Yao YH, Li BG, Yang Q, Zhang PY and Wang HT: Prognostic value of pretreatment serum lactate dehydrogenase level in patients with solid tumors: A systematic review and meta-analysis. Sci Rep 5: 9800, 2015.
11. Ferrari S, Bacci G, Picci P, Mercuri M, Briccoli A, Pinto D, Gasbarrini A, Tienghi A and Brach del Prever A: Long-term follow-up and post-relapse survival in patients with nonmetastatic osteosarcoma of the extremity treated with neoadjuvant chemotherapy. Ann Oncol 8: 765-771, 1997.

12. Durnali A, Alkis N, Cangur S, Yukruk FA, Inal A, Tokluoglu S, Seker MM, Bal O, Akman T, Inanc M, et al: Prognostic factors for teenage and adult patients with high-grade osteosarcoma: An analysis of 240 patients. Med Oncol 30: 624, 2013.

13. Chen J, Sun MX, Hua YQ and Cai ZD: Prognostic significance of serum lactate dehydrogenase level in osteosarcoma: A meta-analysis. J Cancer Res Clin Oncol 140: 1205-1210, 2014.

14. Riley RD, Burchill SA, Abrams KR, Heney D, Sutton AJ, Jones DR, Lambert PC, Young B, Wailoo AJ and Lewis IJ: A systematic review of molecular and biological markers in tumours of the Ewing's sarcoma family. Eur J Cancer 39: 19-30, 2003.

15. Bacci G, Forni C, Longhi A, Ferrari S, Donati D, De Paolis M, Barbieri E, Pignotti E, Rosito P and Versari M: Long-term outcome for patients with non-metastatic Ewing's sarcoma treated with adjuvant and neoadjuvant chemotherapies. 402 patients treated at Rizzoli between 1972 and 1992. Eur J Cancer 40: 73-83, 2004.

16. Wan W, Lou Y, Hu Z, Wang T, Li J, Tang Y, Wu Z, Xu L, Yang X, Song D and Xiao J: Factors affecting survival outcomes of patients with non-metastatic Ewing's sarcoma family tumors in the spine: A retrospective analysis of 63 patients in a single center. J Neurooncol 131: 313-320, 2017.

17. Fujibuchi T, Miyawaki J, Kidani T, Imai H and Miura H: Prediction of soft tissue sarcoma from clinical characteristics and laboratory data. Cancers (Basel) 12: 679, 2020.

18. Zagars GK, Ballo MT, Pisters PWT, Pollock RE, Patel SR, Benjamin RS and Evans HL: Prognostic factors for patients with localized soft-tissue sarcoma treated with conservation surgery and radiation therapy: An analysis of 1225 patients. Cancer 97: 2530-2543, 2003.

19. Maretty-Nielsen K, Aggerholm-Pedersen N, Safwat A, Jørgensen PH, Hansen BH, Baerentzen S, Pedersen AB and Keller J: Prognostic factors for local recurrence and mortality in adult soft tissue sarcoma of the extremities and trunk wall. Acta Orthop 85: 323-332, 2014.

20. Biau DJ, Ferguson PC, Turcotte RE, Chung P, Isler MH, Riad S, Griffin AM, Catton CN, O'Sullivan B and Wunder JS: Adverse effect of older age on the recurrence of soft tissue sarcoma of the extremities and trunk. J Clin Oncol 29: 4029-4035, 2011.

21. Papworth KE, Arroyo VM, Styring E, Zaikova O, Melin BS and Lupo PJ: Soft-tissue sarcoma in adolescents and young adults compared with older adults: A report among 5000 patients from the Scandinavian Sarcoma Group Central Register. Cancer 125: 3595-3602, 2019

22. Wang X, Liu S, Zhao X, Fang E and Zhao X: The value of C-reactive protein as an independent prognostic indicator for disease-specific survival in patients with soft tissue sarcoma: A meta-analysis. PLoS One 14: e0219215, 2019.

23. Idowu OK, Ding Q, Taktak AFG, Chandrasekar CR and Yin Q: Clinical implication of pretreatment neutrophil to lymphocyte ratio in soft tissue sarcoma. Biomarkers 17: 539-544, 2012.

24. Liu G, Ke LC and Sun SR: Prognostic value of pretreatment neutrophil-to-lymphocyte ratio in patients with soft tissue sarcoma: A meta-analysis. Medicine (Baltimore) 97: e12176, 2018.

25. Li Y, Liu X, Zhang J and Yao W: Prognostic role of elevated preoperative systemic inflammatory markers in localized soft tissue sarcoma. Cancer Biomarkers 16: 333-342, 2016.

26. Liang Y, Wang W, Que Y, Guan Y, Xiao W, Fang C, Zhang X and Zhou Z: Prognostic value of the fibrinogen/albumin ratio (FAR) in patients with operable soft tissue sarcoma. BMC Cancer 18: 942,2018

27. Szkandera J, Gerger A, Liegl-Atzwanger B, Stotz M, Samonigg H, Ploner F, Stojakovic T, Leithner A and Pichler M: Pre-Treatment anemia is a poor prognostic factor in soft tissue sarcoma patients. PLoS One 9: e107297, 2014.

28. Li S, Yang Q, Wang H, Wang Z, Zuo D, Cai Z and Hua Y: Prognostic significance of serum lactate dehydrogenase levels in Ewing's sarcoma: A meta-analysis. Mol Clin Oncol 5: 832-838, 2016.

29. Miao P, Sheng S, Sun X, Liu J and Huang G: Lactate dehydrogenase a in cancer: A promising target for diagnosis and therapy. IUBMB Life 65: 904-910, 2013. 
30. Shinohara N, Nonomura K, Abe T, Maruyama S, Kamai T, Takahashi M, Tatsugami K, Yokoi S, Deguchi T, Kanayama $\mathrm{H}$, et al: A new prognostic classification for overall survival in asian patients with previously untreated metastatic renal cell carcinoma. Cancer Sci 103: 1695-1700, 2012.

31. Wan XB, Wei L, Li H, Dong M, Lin Q, Ma XK, Huang PY, Wen JY, Li X, Chen J, et al: High pretreatment serum lactate dehydrogenase level correlates with disease relapse and predicts an inferior outcome in locally advanced nasopharyngeal carcinoma. Eur J Cancer 49: 2356-2364, 2013.

32. Weide B, Richter S, Büttner P, Leiter U, Forschner A, Bauer J, Held L, Eigentler TK, Meier F and Garbe C: Serum S100B, lactate dehydrogenase and brain metastasis are prognostic factors in patients with distant melanoma metastasis and systemic therapy. PLoS One 8: e81624, 2013.

33. Halabi S, Lin CY, Kelly WK, Fizazi KS, Moul JW, Kaplan EB, Morris MJ and Small EJ: Updated prognostic model for predicting overall survival in first-line chemotherapy for patients with metastatic castration-resistant prostate cancer. J Clin Oncol 32: 671-677, 2014
34. Mekenkamp LJ, Heesterbeek KJ, Koopman M, Tol J, Teerenstra S, Venderbosch S, Punt CJ and Nagtegaal ID: Mucinous adenocarcinomas: Poor prognosis in metastatic colorectal cancer. Eur J Cancer 48: 501-509, 2012.

35. Wang X, Jiang R and Li K: Prognostic significance of pretreatment laboratory parameters in combined small-cell lung cancer. Cell Biochem Biophys 69: 633-640, 2014.

36. Nakamura T, Asanuma K, Hagi T and Sudo A: Is serum lactate dehydrogenase useful for predicting oncological outcome in patients with soft tissue sarcoma? Anticancer Res 39: 6871-6875, 2019.

This work is licensed under a Creative Commons Attribution-NonCommercial-NoDerivatives 4.0 International (CC BY-NC-ND 4.0) License. 